\title{
Heart rate measures in blind cave crayfish during environmental disturbances and social interactions
}

\author{
Hao Li, Laura R. Listeman, Devan Doshi, Robin L. Cooper* \\ Thomas Hunt Morgan School of Biological Sciences University of Kentucky, Lexington, KY, 40506-0225, USA
}

Received 11 February 2000; received in revised form 3 May 2000; accepted 8 June 2000

\begin{abstract}
Most animals continually assess the environment in which they live and alter their behavior according to various stimuli. As an observer, one looks for changes in a behavior indicating that an animal responded to a particular event. When the animal does not make significant behavioral changes as measured by bodily movements, the animal may be characterized as unresponsive to a given stimulus. This study demonstrates that when behavioral body movements can not be observed an internal physiological measure of heart rate (HR) shows dramatic changes following presentation of defined stimuli. This study used the blind cave crayfish and examined their responsiveness to the following stimuli: light (infrared, dim red, and white), water-borne vibrations, removal of water, olfactory cues, and social interaction with partners. This study demonstrates that there is substantial individual variation of HR at basal levels and with the intensity of an social interaction. We find HR is a reasonable measure of the responsiveness of blind cave crayfish to given stimuli even in the absence of observable behavioral changes. This enables the observer to determine if an individual is responsive to and making an assessment of particular cues. (C) 2000 Elsevier Science Inc. All rights reserved.
\end{abstract}

Keywords: Heart rate; Crayfish; Crustacean; Social status; Cave; Interactions

\section{Introduction}

The neural integration of sensory information underlies an animal's ability to react to its environment. The ability to react is important, but to know if the stimulus is a threatening signal or environmental noise requires some form of recognition and memory. To understand how animals perceive each other or cues in their environment, a means of observation is required. Past research has primarily emphasized an understanding of sensory systems by examining individual systems and their in-depth function, with little relationship

\footnotetext{
* Corresponding author. Tel.: + 859-257-5950; fax: + 859257-1717.

E-mail address: rlcoop1@pop.uky.edu (R.L. Cooper).
}

to their use by the whole animal With a reductionist approach of measuring primary sensory neuronal activity, degrees in neuron sensitivity can be achieved, but this does not allow one to know how the information is integrated within the animal nor does it allow one to correlate the information to whole animal behavior. In contrast, by only monitoring behavior through visual observation one can be misled in determining if an animal senses an environmental cue or physical interaction. This bias occurs when an animal remains unaltered in the behavior visible to an observer, although internally the animal may well be excited or 'tuned up' during an alteration in its physical environment. By measuring an index of internal state of the an animal during which time sensory cues are experimentally introduced, one 
may obtain additional information about an animal's perception of a stimulus and how long such alterations in an internal state exist. Such measures are able to be extended to animals engaging in assessment of others during social interaction. This approach can provide a window of opportunity for determining not only which sensory cues result in the greatest alterations of internal state, but also which cues are modifiers of motivation to continue a social encounter.

Motivational status has been shown to be altered during various stages of social contest among hermit crabs (Elwood et al., 1998). Also it appears that recent winners or losers of a social combat in crickets alters their behavior for a subsequent interaction but upon an abrupt physical disturbance their social status is lost and the animals will re-engage in combat (Hofmann and Stevenson, 2000). Such levels of motivation may well be related to the levels of circulating neuromodulators which can either tune-up or tunedown sensory input, central integration, and motor output (Sneddon et al., 2000). For example, in crayfish application of $100 \mathrm{nM}$ 5-HT enhances primary sensory neuron sensitivity, alters integration in the ventral nerve cord of sensory input, and increases the firing frequency of the motor neurons (Pasztor and Bush, 1987; Pasztor and MacMillan, 1990; Strawn et al., 1999a,b). Additionally, 5-HT increases transmitter release at neuromuscular junctions, and alters the input resistance directly of muscle fibers (Dudel, 1965; Strawn et al., 1999a,b; Southard et al., 2000; Crider and Cooper, 1999). In contrast, the molting hormone, ecdysone, has been shown to depress synaptic transmission (Cooper and Ruffner, 1998). Humoral neuromodulators are known to have direct effects on HR (Florey and Rathmayer, 1978; Wilkens and McMahon, 1992). Thus, it is feasible that HR may be indicative of motivational status and could be used to predict the level of responsiveness to various stimuli (Listerman et al., 2000).

Crustacean models are useful for studying the mechanisms underlying behavior because of the relatively simplicity of the nervous system as compared to vertebrates. Crayfish offer an advantage because of the ease in experimentation from which recordings are made of motor neurons, sensory neurons, and neuromuscular junctions. In addition, crayfish have stereotypical aggressive and submissive behaviors (Bruski and Dunham,
1987) as has also been shown in lobsters (Huber and Kravitz, 1995). Combative interactions with other crayfish may be less likely to occur if an opponent is sensed earlier, providing more time to flee. In the sighted crayfish, vision provides this sensing ability. It is not known if blind cave crayfish possess a better ability to sense through tactile or chemical modalities. Animals that have evolved to their particular environments make use of sensory information in various manners which in time can result in altered anatomical and physiological abilities. Morphological studies of crayfish fossils and geological evidence suggest that the Orconectes of the Cumberland Plateau in Kentucky entered the karst systems during the Miocene period (Rhoads, 1944, 1962; Hobbs and Barr, 1960; Hobbs et al., 1977; Barr, 1985). This extent of time suggests that many variations in the sensory systems among cave crayfish of isolated cave systems have had time to develop.

The blind cave crayfish used in this study, Orconectes australis packardi Rhoads, live in a cave environment with water in which no light is present. These cave crayfish possess elongated antennae as compared to sighted crayfish. It is likely that this morphological characteristic is an adaptive trait for life in a cave. Such troglomorphic traits of elongated antennae and reduced eyes of the amphipod crustacean Gammarus minus was shown to be genetically determined and that natural selection may be responsible for their evolution (Culver et al., 1995).

In an earlier study (Listerman et al., 2000), we have shown the significance of obtaining physiological measures of HR in crayfish prior to, during, and after social interactions of both the aggressive and submissive individuals in the sighted crayfish, Procambarus clarkii. In addition, we performed correlative measures of HR and induced systemic levels of serotonin (5-HT) by injection into the hemolymph to determine the effects of such systemic concentrations on HR. 5-HT is known to alter behaviors (i.e. feeding and reproduction) and is thought to regulate aggressive and submissive social status. In the past study, we showed that HR serves as an index for the effects of circulating 5-HT in a concentration dependent manner (Listerman et al., 2000). However we are not convinced that aggressive individuals exhibit a high systemic level of 5-HT, because basal HR is not higher than that measured for submissive individuals. Also, injections which pro- 
duced circulating concentrations of $100 \mathrm{nM}$ resulted in a sustained elevated HR which is not observed in an aggressive crayfish just after it wins an interaction.

Since the species of cave crayfish used in this study has a non-functional visual system (Cooper et al., 1998; Cole et al., 1998), it would not be surprising that either tactile and/or olfactory sensory systems are enhanced. Here we establish that $\mathrm{HR}$ is a useful index to use in the blind cave crayfish as a means of monitoring internal status during social interactions and during alterations in their aquatic environment. We plan to use the data from this study for comparison with sighted crayfish during social interactions and the presentation of sensory stimuli, with vision being restricted either by use of infrared lighting or by placing caps over the eye stalks.

Portions of this data have previously been presented in abstract form ( $\mathrm{Li}$ et al., 1998; $\mathrm{Li}$ and Cooper, 1999; Listerman et al., 1999).

\section{Methods}

\subsection{Animals}

The animals used in these experiments were adult male blind cave crayfish $-O$. australis packardi Rhoads. Blind cave crayfish of varying size (2.0-2.5 cm carapace length), were collected from Sloan's Valley Cave, near Somerset, KY. Animals were brought to the laboratory in Lexington and kept in a dark room $\left(14-15^{\circ} \mathrm{C}\right.$ within individual aquaria $(34 \times 21 \times 23 \mathrm{~cm}$; water depth $10-15 \mathrm{~cm})$ for 10-14 days. Upon arrival, the specimens were size-matched (carapace length) and labeled on the carapace with white fingernail polish. They were fed twice a week with fish food pellets.

\subsection{Recording procedures}

The same procedures were used as described in an earlier study for obtaining electrocardiograms (ECGs) (Listerman et al., 2000). In brief, two insulated iridium/platinurn wires (diameter 0.005 inches and with the coating 0.008 inches; A-M systems, Inc., Carlsburg, WA) were placed under the dorsal carapace directly over the heart. Wires were inserted through holes drilled in the carapace and cemented in place with instant adhesive (Eastman, 5 min drying epoxy). These two wires were placed to span the heart in a rostral-caudal arrangement to insure an accurate impedance measure during each contraction. As with previous investigators, we found that prolonged handling stresses the animals and alters the physiological measurements for a time duration of $24 \mathrm{~h}$ to 3 days (Wilkens et al., 1985; Listerman et al., 2000).

Impedance detectors (UFI, model 2991) were used, which allowed HR to be monitored as a measure of dynamic resistance. These signals were recorded to a VHS tape (Vetter, 400) and on line to a PowerMac 9500 via a MacLab/4s interface (ADInstruments). All events were measured and calibrated with the MacLab Chart software version 3.5.6 (ADInstruments, Australia) with an acquisition rate set at $4 \mathrm{kHz}$ for ECGs.

The heart rates were determined by direct measures with a window discriminator of an instantaneous measure. The values were then converted to beats per $\min (\mathrm{BPM})$.

\subsection{Behavior}

To test animal sensitivity to particular environmental alterations, the study was divided into five parts: (1) alteration in exposure of infrared, dim red and white light; (2) disturbance of the water in front of a stationary individual by dropping a drop of water or a pebble; (3) adding water to the tank which was conditioned with an isolated crayfish for 1 week; (4) removing the water from the tank or adding water; and (5) pairing two conspecific individuals for interaction.

The first series of experiments in altering the lighting source, stemmed from an earlier study in which we had shown that white light causes the cave crayfish to seek shelter (Li and Cooper, 1999). The infrared light was provided by the use of an IR source. The individual behaviors as well as the interactions of crayfish were taken using an infra-red sensing CCD camera (Toshiba, model IK-537A) fitted with a zoom lens (Pentax TV, zoom 8-48 $\mathrm{mm}$ ) and a video cassette recorder (Panasonic, time lapse SVHS, model AG6T20). Recordings were analyzed using direct viewing of the video data on a TV screen (17 inches across). The crayfish were allowed to adapt to the chamber and to being wired for recording, usually for 3 days prior to the recording. This period is needed to allow the crayfish to settle down in a 
new environment (Bruski and Dunham, 1987; Listerman et al., 2000). Dim red light was given by using white light fitted with a white light filter (Edmond Scientific, \# D43,951). White light was supplied by a 40-watt incandescent bulb in a removable lamp. All light sources were placed $1.83 \mathrm{~m}$ above the observation tanks.

Disturbance of the water in front of a stationary individual by dropping a drop of water or a pebble while monitoring HR allowed us to assess the response of the animal. Dramatic behavioral changes in body movements were not always apparent. The drop of water was given from 1 meter height and $12 \mathrm{~cm}$ in front of the animal while the water depth within the tank was $8 \mathrm{~cm}$. A small pebble $(\sim 0.15 \mathrm{~g})$ was dropped under the same conditions. HR was continuously monitored until HR returned to basal levels. Dim red lighting was used in these conditions.

The experiments which involved draining or adding water were done so by a large-bore (1 inch diameter) plastic tube that was fitted to the hole in the base of the tank. The other end was attached to a glass container which could be raised or lowered in relation to the observation tank. This allowed adjustment of the water level in which the crayfish were exposed. When the water was drained only moist sand remained in the tank for the animals to walk on. These experiments were done in dim red light conditions.

Adding water which contained water from another male's tank was done in the same manner with the exception to insure that the original water level was increased two fold. This allowed a consistent alteration in water level and dilution of added water. The crayfish conditioned water consisted of an intermolt male crayfish that was allowed to freely move in its tank for 1 week. Thus excreted products were allowed to build up for the entire week.

For the paired interactions, the partners were placed in individual tanks and gently moved to a novel fresh tank, to study initial interaction. Since all recordings of behavior and electrophysiological responses displayed on the oscilloscope were captured together on video, the behaviors could be precisely sequenced with the ECG recordings. Dim red lighting was used in these studies.

\subsection{Statistical analysis}

The data taken in sequence over time were examined for trends with a one-way repeated measures ANOVA. In comparing groups of data for significance either a Student-Newman-Keuls: test or a Dunnett's test was used.

\section{Results}

The blind cave crayfish, $O$. australis packardi Rhoads, has elongated antennae as compared to some sighted crayfish species (i.e. $P$. clarkii) which would likely allow them a greater ability to sense vibrations within the water (Fig. 1A). The long antennae would also allow the animal to contact objects far in advance of their main body when walking. The animals also do not possess pigment in their eyes (Fig. 1B).

\subsection{Effects of light on $H R$}

Since this species of cave crayfish does not have ommatidial structures and lacks pigment in the eye, it is assumed that it is blind (Cooper et al., 1998). Even though cave crayfish do not have developed eyes they are still responsive to white light presumably by the use of a caudal photoreceptor. Such responses have been shown in the Missouri cave crayfish C. setosus (Larimer, 1966) and in the species used in this current study ( $\mathrm{Li}$ and Cooper, 1999). In preliminary studies, we examined whether infrared, dim red and white light had an effect on the behavior of the cave crayfish. It appears that only the white light stimulated the animals to walk in search of a dark place, which they appeared to prefer over lighted areas (Li and Cooper, 1999). The light drives the animal to move. The present study indicates that infrared or dim red lighting did not result in an elevated HR (Fig. 2) but that exposure to white light resulted in an increase in HR not only during the walking phases (the peaks shown in the figure) but between walking phases as well. The small peaks during infrared or dim red lighting are due to movements of the chelae or the walking legs, which appear to be associated with grooming or undescribed acts. The largest increase in HR, upon exposure to white light, took place within the first $30 \mathrm{~min}$. In some cases HR subsided to, or close to, baseline levels within an hour even in the continuous presence of white light. There was a significant elevation in HR from baseline for all five animals for at least the 


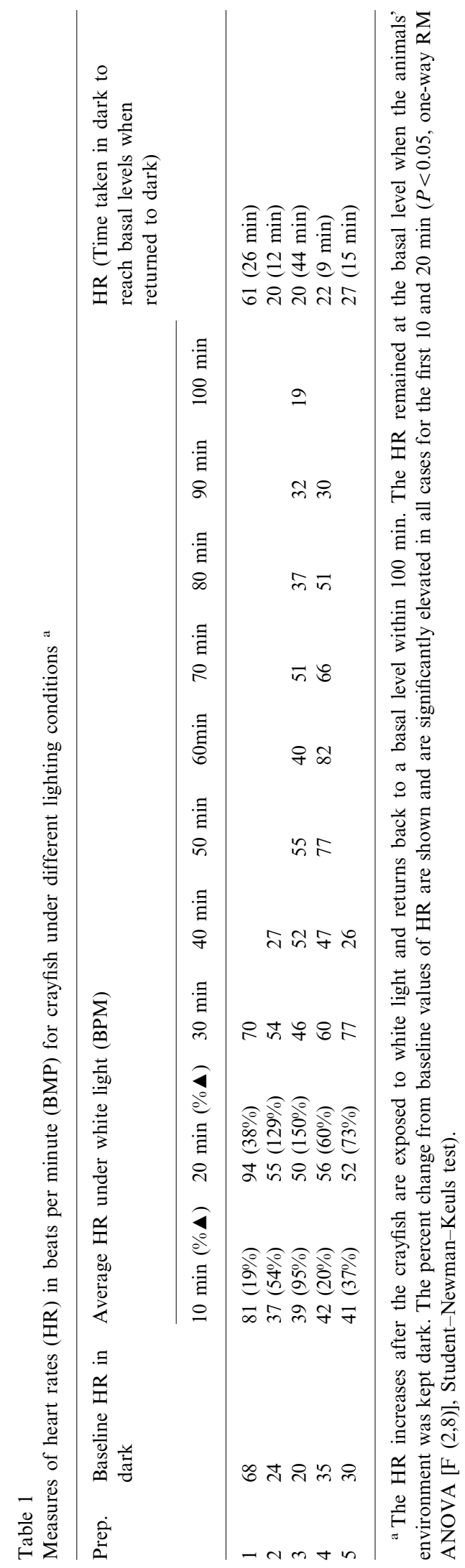


first $20 \min (P<0.05$, one-way RM ANOVA $[F$ $(2,8)]$, Student-Newman-Keuls test) and for four of the five animals for a total of $40 \mathrm{~min}$. However, in some of the animals HR remained elevated for more than an hour (Table 1).

\subsection{Slight vibrational disturbances in the water}

Even though the crayfish did not appear to be responsive behaviorally to a water droplet, their HR increased, which indicated that they were very
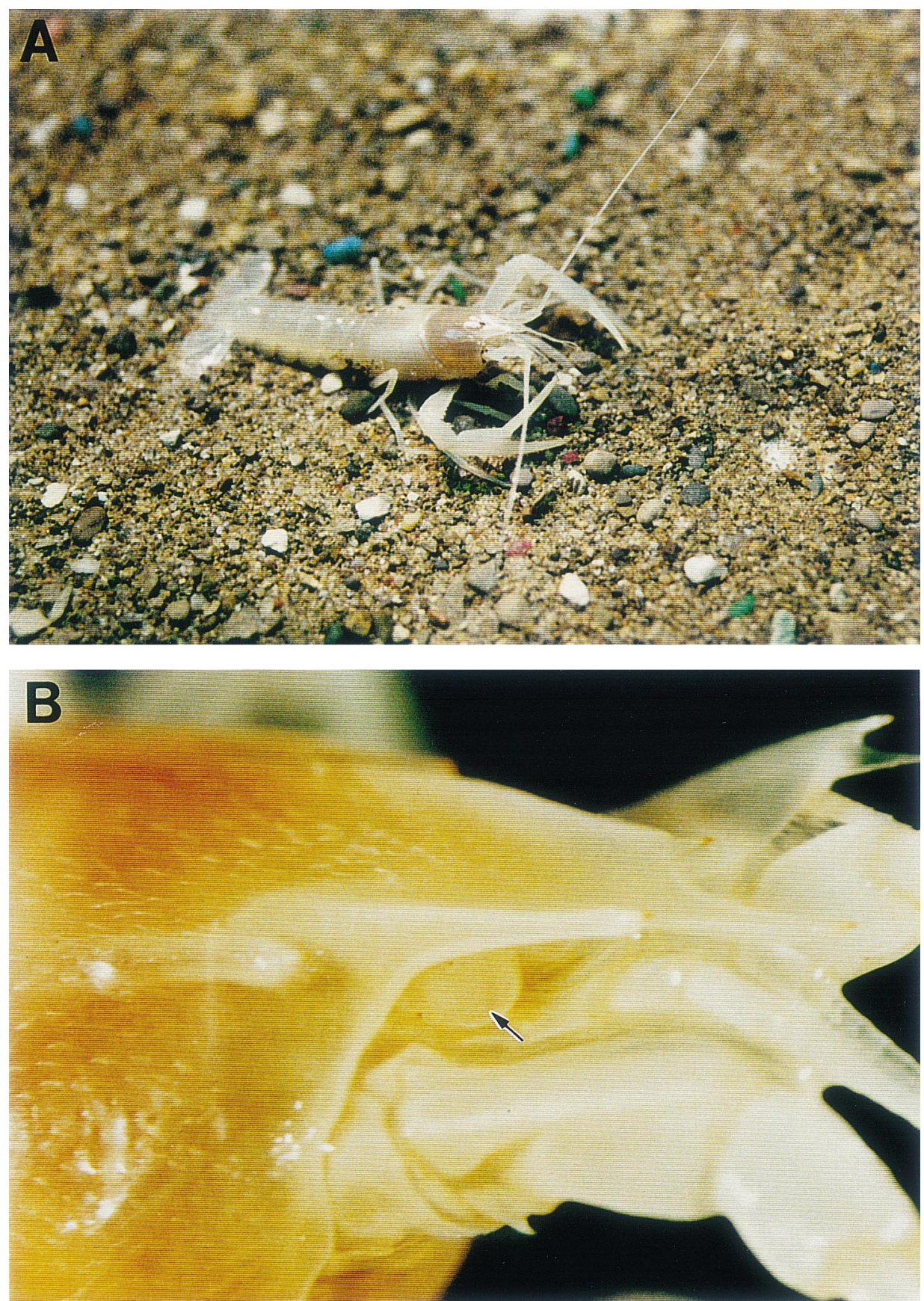

Fig. 1. The blind cave crayfish, Orconectes australis packardi Rhoades, commonly found within the Sloan's Valley cave system in Kentucky (A). This species of crayfish have elongated antennae and residual eyes without pigmentation (B). 


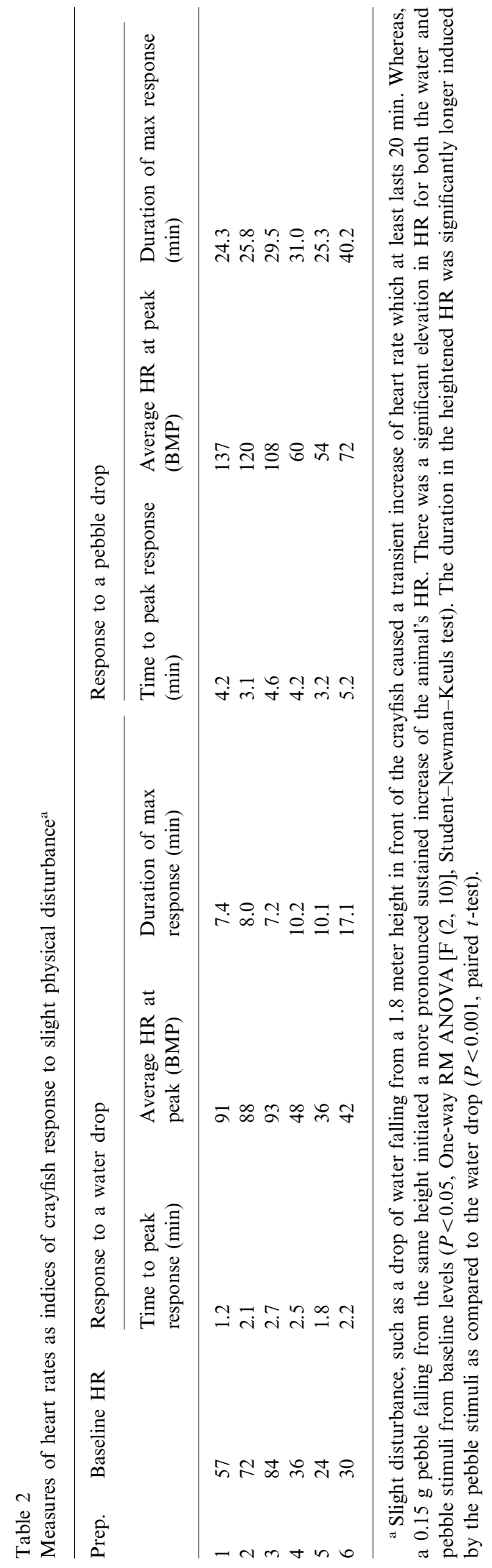


A
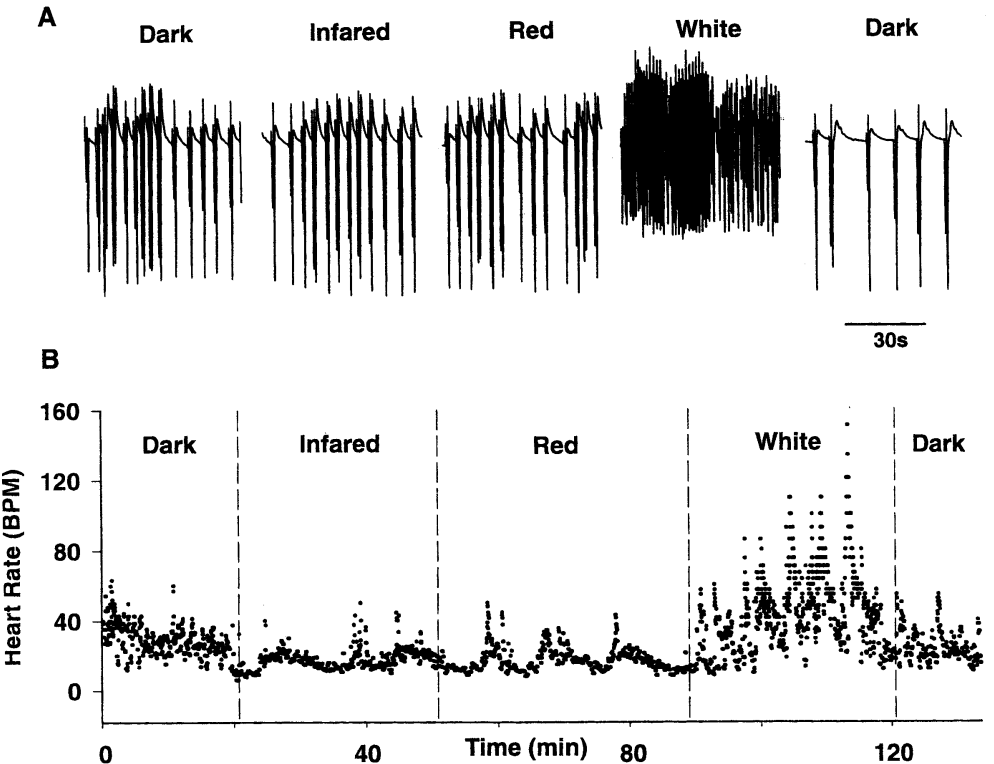

Fig. 2. Heart rate (HR) was recorded under different lighting conditions: infrared, dim red, and white light. Typical activity profiles are shown in A for each lighting condition (each trace is for $1 \mathrm{~min}$ ). The beats per minute (BPM), calculated for each event, shows that heart rate is significantly elevated in white light and that the animals are non-responsive to infrared and dim red lighting (B).
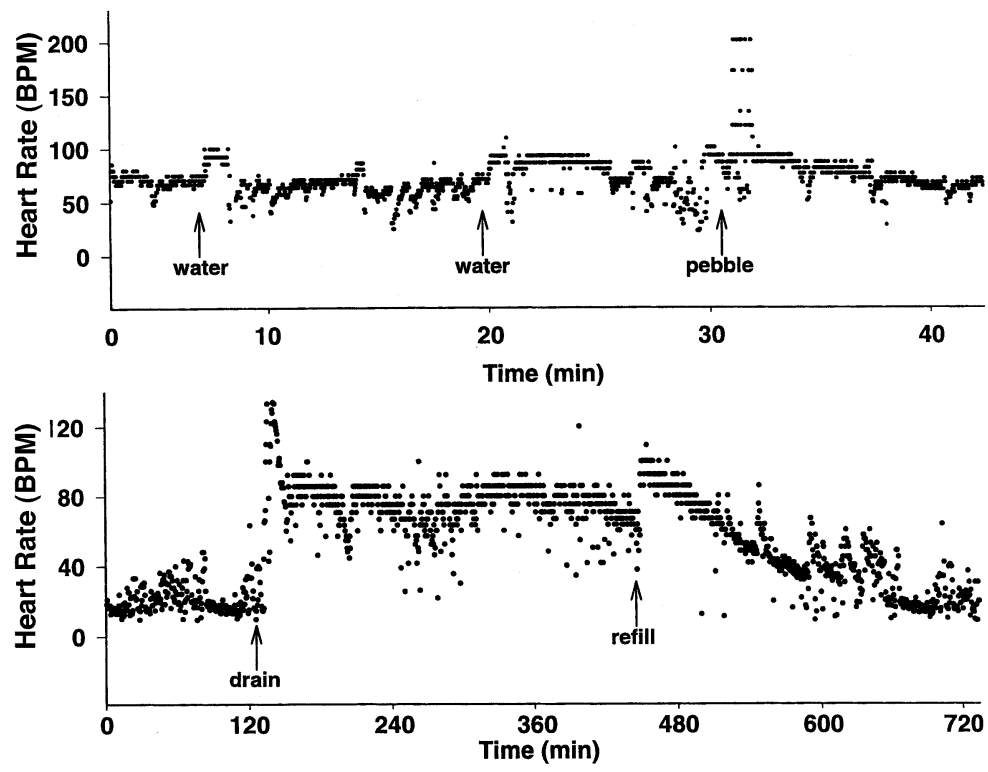

Fig. 3. Changes in HR are correlated to physical disturbance upon the animals aquatic environment. (A) A drop of water falling from $1 \mathrm{~m}$ and $2.5 \mathrm{~cm}$ in front of the animal, caused a brief increase in heart rate which lasts a few minutes. A more dramatic duration in an elevated heart rate was induced after a $0.15 \mathrm{~g}$ pebble was dropped from the same height. (B) Alterations in the water level also resulted in changes in HR. The HR is elevated after water is drained and sustained until the chamber is refilled with its original water. A brief increase in HR is also observed when the water is initially refilled.

much aware of the stimulus. In some trials, HR only increased for a minute, while in other trials HR remained elevated for several minutes (Fig. 3A). There was substantial variation of basal HR among individuals as well as in the rate, degree and duration of response to the standardized water drop stimulus (Table 2). Only an initial response was quantified for comparisons in Table 2. 
There was a significant elevation in HR for both the water and pebble stimuli from baseline levels $(P<0.05$, One-way RM ANOVA $[F(2,10)]$, Student-Newman-Keuls test). In Fig. 3, two repetitive tests are shown to illustrate variation in the response. Slightly larger stimuli, such as that induced by a small pebble instead of a water droplet, caused a larger increase in $\mathrm{HR}$ and the duration in the elevated $\mathrm{HR}$ to be more pronounced (Fig. 3A and Table 2). The duration in the heightened HR was significantly longer induced by the pebble stimuli as compared to the water drop $(P<0.001$, paired $t$-test $)$. Such stimuli as a water drop or an object (such as a cave cricket) dropping into a pool would not be an uncommon occurrence in some regions of a cave.

\subsection{Substantial disturbances in the volume of a pool}

Within the particular region of the cave from which these crayfish were obtained, seasonal effects of surface water runoff and snow melt can rapidly alter the volume of a pool. Also, when the fine mud on the floor of the cave washes out or gives way to deeper drainage, a pool can rapidly disappear leaving a crayfish on moist substrate. In simulating such alterations in pool existence within the laboratory it was apparent that the HR of the crayfish responded markedly even in the absence of walking movements (Fig. 3B). It is worthy to note that HR rapidly increased upon the initiation of water flowing past the animal as it was drained from a port in the bottom of the experimental tank. The animal did not appear to walk but positioned itself in and out of the water flow with a few side turns. Upon re-creation of a pool of water. the animal's HR gradually decreased back to a basal level. The peaks in HR as the water is added back, in the representative animal (Fig. 3B), are due to bodily movements of the animal exploring the environment. The elevated $\mathrm{HR}$ of the animals in the drained pools remained higher than basal levels for several hours (Table 3 ). This maintained HR could likely be due to a physiological need of the skeletal muscle's metabolism, since the muscles in the legs and thorax have to exert a greater force to keep the body in an upright position out of the water. In most cases, the addition of the same water back to the animal's environment would gradually result in HR slowing down back to baseline levels within a few hours. As with the previous experimental manipulations, on different sets of crayfish, there was substantial individual variation (Table 3). In comparing the percent change during the first $30 \mathrm{~min}$ for either draining the water or adding water back to the tank, HR was significantly higher than baseline conditions $(P<0.05$, One-way RM ANOVA $[F(2,10)]$, Student-Newman-Keuls test).

\subsection{Olfactory effects on $H R$}

As with the light and tactile stimuli, it is apparent that an olfactory cue can also result in an altered HR in the absence of behavioral changes. The addition of an olfactory cue to a body of

Table 3

Measures of heart rates (BPM) for individual crayfish before and after water removal, followed by refilling with the original water ${ }^{\mathrm{a}}$

\begin{tabular}{|c|c|c|c|c|c|c|c|c|c|c|c|c|c|c|}
\hline \multicolumn{2}{|c|}{$\begin{array}{l}\text { Prep. baseline HR in } \\
\text { water }\end{array}$} & \multicolumn{6}{|c|}{$\begin{array}{l}\text { Average HR after the water was drained } \\
(\mathrm{BPM})\end{array}$} & \multicolumn{6}{|c|}{ Average HR after refilling water (BMP) } & \multirow[t]{2}{*}{ HR \& time } \\
\hline & & $30 \min (\% \mathbf{\Delta})$ & $1 \mathrm{~h}$ & $2 \mathrm{~h}$ & $3 \mathrm{~h}$ & $4 \mathrm{~h}$ & $5 \mathrm{~h}$ & $30 \min (\% \mathbf{\Delta})$ & $1 \mathrm{~h}$ & $2 \mathrm{~h}$ & $3 \mathrm{~h}$ & $4 \mathrm{~h}$ & $5 \mathrm{~h}$ & \\
\hline 1 & 22 & $84(282 \%)$ & 80 & 67 & 82 & 78 & 67 & $88(300 \%)$ & 67 & 52 & 44 & 24 & 20 & \\
\hline 2 & 47 & $85(81 \%)$ & 90 & 79 & 64 & 80 & 66 & $92(96 \%)$ & 72 & 70 & 74 & 65 & 52 & $44(6.2 \mathrm{~h}$ \\
\hline 5 & 72 & $127(76 \%)$ & 114 & 118 & 122 & 109 & 104 & $122(66 \%)$ & 114 & 103 & 92 & 70 & & \\
\hline 6 & 64 & $140(119 \%)$ & 129 & 130 & 98 & 113 & 102 & $144(125 \%)$ & 121 & 100 & 94 & 70 & 62 & \\
\hline
\end{tabular}

\footnotetext{
${ }^{a} \mathrm{H}$ increases as the animal's pool of water is diminished. The FIR remains elevated for the $5 \mathrm{~h}$ experimental duration of the animal being exposed to only moist substrate. As the water is returned to the animals chamber a further brief increase in HR is observed which gradually returns to a basal HR level in a few hours. Time refers to the overall time taken for HR to return to a basal state. In comparing the percent change during the first $30 \mathrm{~min}$ for either draining the water or adding water back to the tank HR was significantly higher than baseline conditions $(P<0.05$, One-way RM ANOVA $[F(2,10)]$, Student-Newman-Keuls test).
} 


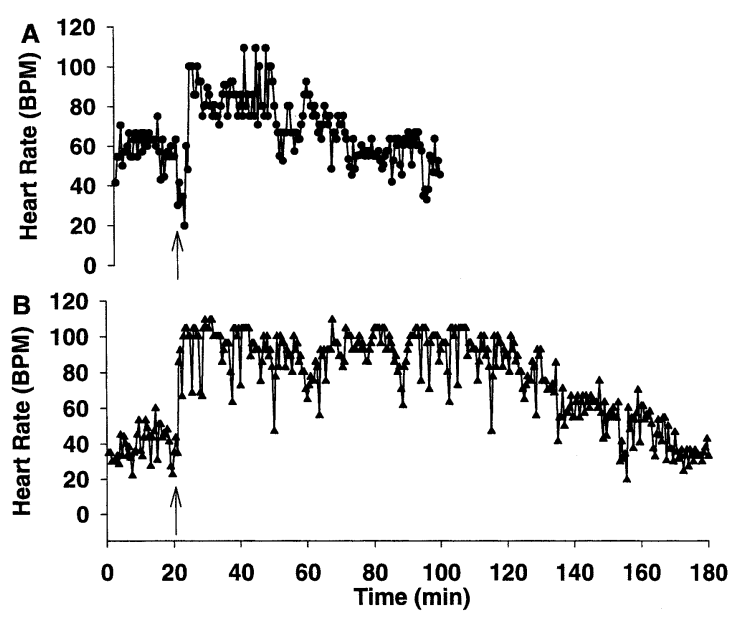

Fig. 4. Response induced by olfaction independently of tactile sense was approached by added $50 \mathrm{mls}$ of water either from the animals own tank (sham, A) or $50 \mathrm{mls}$ of water taken from a donors tank (experimental, B). Adding the original water causes HR to increase for about $1 \mathrm{~h}$ due to the physical disturbance. Introducing $50 \mathrm{mls}$ of conditioned water from a donor male crayfish resulted in a sustained increased in heart rate lasting at least twice as long as controls. Water was introduced at the times marked with arrows. The recordings were terminated upon recover of HR to baseline conditions.

water, as in our experimental condition, results in movement of the water which will stimulate a vibrational response as well as an olfactory one, if an odorant is contained in the added water. To control for the disturbance of adding $50 \mathrm{ml}$ of water, water was previous removed from the tank ( $5 \mathrm{~h}$ previously), and in the controls (i.e. sham) the same water was added back. The experimental animals had $50 \mathrm{mls}$ of water added to their tanks which was obtained from a single donor crayfish tank. The water from the donator's tank had been conditioned for 1 week with the presence of a single large male crayfish. The addition of the water to the observational tanks occurred when the animals were on one side of their tank so that the $50 \mathrm{mls}$ of water could be added to the opposite side. The water was gently added within the body of water to avoid large surface disturbances. In all cases, the addition of the water resulted in an initial decrease of HR. In the five sham experiments, the HR returned close to baseline within an hour and half. In these cases in which conditioned water was added, the animals HR increased to higher levels and was maintained at an elevated HR for longer times (Table 4). In comparison to baseline conditions HR decreased significantly for all animals within the first $5 \mathrm{~min}$ and increased at the $40 \mathrm{~min}$ period but not at the 20 min time point $(P<0.05$, One-way RM ANOVA $[F(3,12)]$, Dunnett's test). Each measurement point was an average from the previous time point. The duration of the elevated HR is significantly longer for the experiments in which conditioned water was used $(P<0.05$, paired $t$-test $)$. Representative animals are shown in Fig. 4 for the sham (Fig. A) and the conditioned water (Fig. B). Possibly more subtle techniques of adding olfactory cues would provide a more refined approach to investigate olfactory cues on the effects of regulating the responses observed on HR.

\subsection{HR during social encounters}

Since the cave crayfish can not see each other they are most likely able to sense each other by tactile or olfactory con-specific cues. Whereas for sighted crayfish, the visual stimulus of another crayfish is enough to cause HR to increase for either the eventual dominant or the submissive individuals (Listerman et al., 2000). To investigate if the blind cave crayfish also alter their HR during social interactions, isolates were paired and allowed to interact while their HR was monitored. When individuals came close to each other without physical contact HR increased indicating that they could sense each other. It is likely that either a tactile stimulus or the combination of a tactile and an odoriferous stimulus caused the individuals to respond. This can happen by a gill current which is forced in front of an individual, projecting urine with the current (Atema, 1986; Cheng and Chang, 1991; Dunham, 1988). A representative pair of crayfish during social encounters is illustrated in Fig. 5. When initial contact was made by antennae touching, HR increased sharply in some instances, although in this illustrative case HR only rose in one individual (see Fig. 5 at 15:00 min:s). Likewise during the other physical contacts, crayfish \# 2 was not as reactive as crayfish \# 1 . When the two actually held each other's chelae HR showed a drop followed by a rise which again was more pronounced for the \# 1 crayfish of this pair. Each pair examined showed a large variation in their initial HR and alteration in HR upon similar behavioral acts (Table 5). Four easily identifiable acts were monitored among three pairs of crayfish upon initial interactions after being held as isolates for 2 weeks. The four behavioral acts of walking, an- 


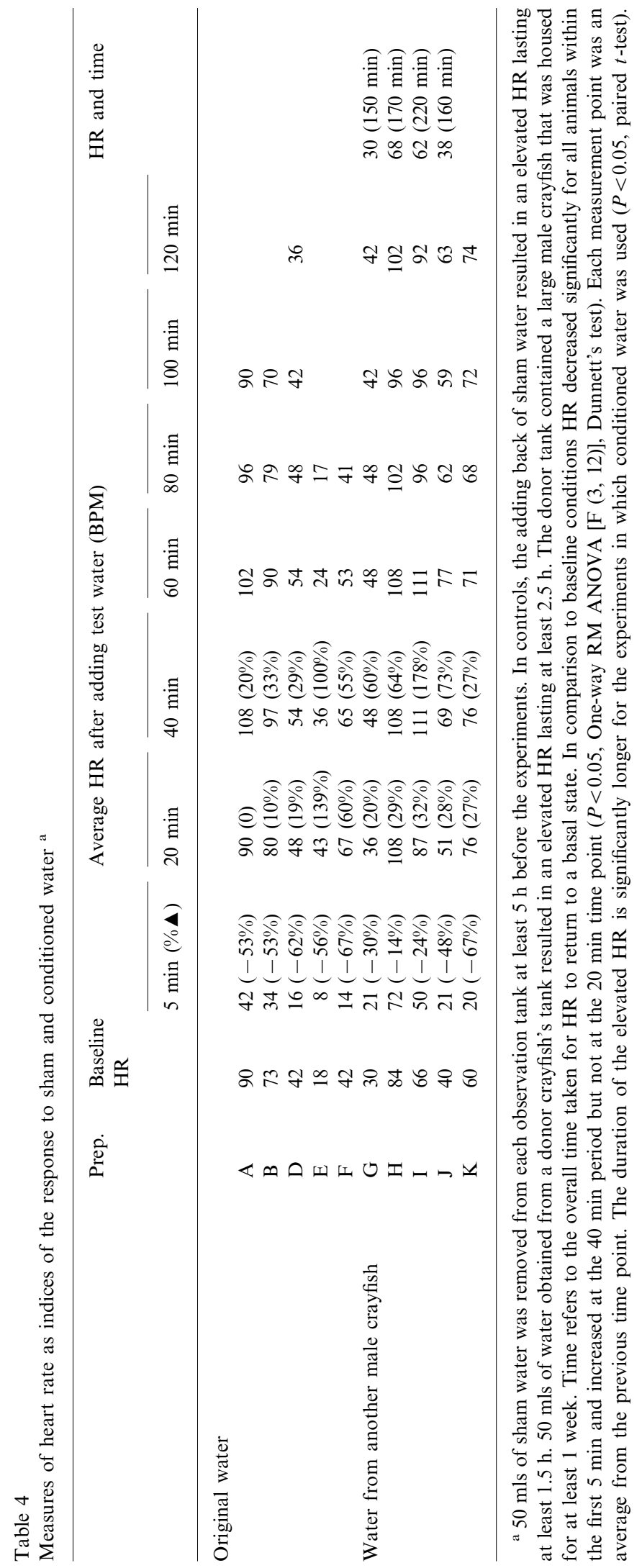




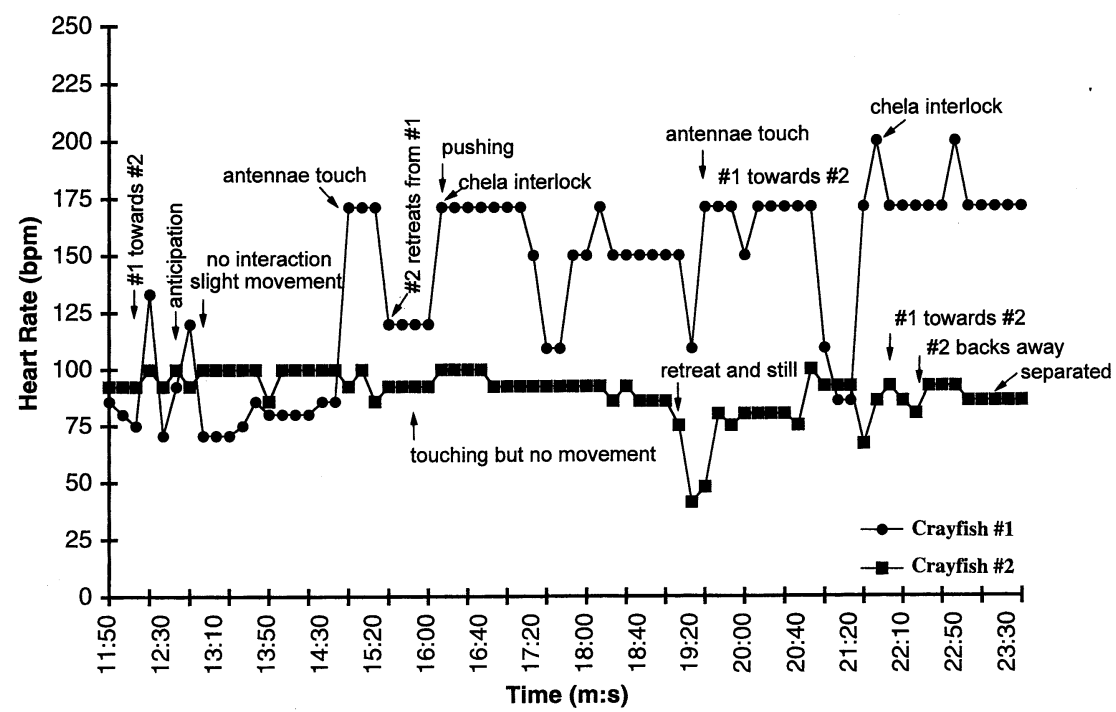

Fig. 5. Social interactions of the blind cave crayfish reveal that the animals HR can vary depending on the type of interaction and that the degree of change is individually variant. Pair wise interactions of previously isolated blind crayfish demonstrated particular social behaviors, as indicated on the graph. These observed behaviors and alterations in HR can be correlated. For example, when the crayfish walk HR will increase slightly but when they interact by either holding on to each other or pushing each other HR will elevate rapidly and remain elevated during the interaction. It does not appear that a submissive or dominate distinction can be made based on differences in HR measures even when one animal is clearly assertive to the other individual.

tennae touching, tail flip and full interaction of pushing each other did not necessarily occur in the order presented in Table 5. It is also hard to assess the amount of force in which a pair engaged during a pushing match or if other signals occurred that were non-visible to the observer, such as odor and gill currents. From the social interaction results it is clear that individual variation is present and that various types of interac- tion can result in different alterations in HR. For example the more physical the interaction, such as with a pushing match with chelae, the HR rose even higher. The smaller changes occurred with the non-physical contact interactions. There was significant increases in HR from baseline levels for all four behavioral acts when the behavioral acts are treated as a group $(P<0.05$, Dunnett's test).

Table 5

ECGs associated with characteristic social behaviors ${ }^{\text {a }}$

\begin{tabular}{llccccc}
\hline & Prep. & Baseline HR (Mean \pm S.E.) & Walking & Antennae touch/anticipation & Tailflip/retreat & Interaction \\
\hline Pair 1 & A & $115 \pm 17.5$ & 120 & 100 & 240 & 300 \\
& B & $113 \pm 18.4$ & 120 & 110 & 125 & 130 \\
Pair 2 & C & $77 \pm 15.5$ & 105 & 100 & 120 & 170 \\
& D & $100 \pm 8.7$ & 120 & 110 & 120 & 170 \\
Pair 3 & E & $57 \pm 10.0$ & 90 & 120 & 105 & 114 \\
& F & $55 \pm 9.5$ & 110 & 100 & 125 & 110 \\
Pair 4 & G & $60 \pm 5.2$ & 79 & 76 & 103 & 126 \\
& H & $68 \pm 7.9$ & 82 & 72 & 98 & 172 \\
Pair 5 & I & $64 \pm 2.8$ & 72 & 55 & 92 & 166 \\
& J & $70 \pm 4.9$ & 86 & 92 & \\
\hline
\end{tabular}

\footnotetext{
${ }^{a}$ Four behaviors that are readily distinguishable were used among three pairs of socially interacting crayfish and the HR during these behaviors are reported. There was significant increases in HR from baseline levels for all four behavioral acts when the behavioral acts are treated as a group $(P<0.05$, Dunnett's $t$ est $)$.
} 


\section{Discussion}

The results of this study indicate that the blind cave crayfish are sensitive to small disturbances in their environment as measured by changes in HR. Even though the crayfish did not evoke behavioral responses that are directly visible by an observer, the internal state of the animal was measurably affected. The degree and duration of the alteration in HR was related to the intensity of the environmental disturbance. This study also indicates that HR as an internal measure is useful when two crayfish are assessing each other during a social interaction. We now know how crayfish internally respond to a slight tactile touch by an antenna or during escalation of an interaction, where previously observers had to rely on measurable body movements.

The sensitivity of these blind cave crayfish to a water or a pebble drop in their environment suggests that various degrees of alertness may exist within the crayfish, for them to react to a subsequent stimulus. Thus the latency of behavioral acts and motivational states may well exist in crayfish. Such varied intrinsic states are suggestive of an autonomic system common to vertebrates. The 'fight or flight' response of the vertebrate sympathetic nervous system could likely have an analog in invertebrates (Wilkens and McMahon, 1992; McMahon, 1995; Burmistrov and Shuranova, 1996). If this is so, then HR may be a means by which internal state can be correlative to motivational levels to be determined prior to engaging in an interaction or to determine at what level of intensity an interaction may start. More work is needed to finely tune HR measures with various behavioral acts prior to and during social interactions. Such measures may then be suggestive of the likely outcome of a particular social interaction before it has even taken place.

The behavioral acts during social interactions that are observable, such as antenna touching, a tail flip, or a pushing battle results in an elevated HR that would be predicted by the intensity of the interaction. For example, a tail flip results in the animal having an elevated HR for a few minutes afterwards but a pushing battle can sustain a higher HR throughout the physical interaction. Likewise when two individuals are assessing each other, after some time of being acquainted with the environment and each other, antenna touching does not result in such a large increase in
HR. However, HR can remain elevated during the several minutes of antenna touching until one individual backs away or an escalation takes place. The visual assessment of antenna touching and HR levels is one correlative measure, but it does not allow the observer to determine the influence of the olfactory assessment which is on going simultaneously. Lobsters, for example, are known to increase their gill current, which carries along urine, toward a facing opponent (Breithaupt and Atema, 1993). This is likely a form of chemical communication used during crustacean social interaction (McLeese, 1973). There is evidence that the urine contains substances unique to an individual which could be a method for social status recognition within a population (Karavanich and Atema, 1998). The present study has shown that adding primed water obtained from another male's tank to an isolated individual's tank causes HR to increase more, and for a longer duration, than for sham experiments. This indicates that the chemical sensing ability of another crayfish is present and that it affects the animal enough to alter HR. During the addition of the control water or the tainted crayfish water the crayfish being monitored does not visually appear to react except for the fact of standing still and moving the antenna in a horizontal sweeping motion. This again illustrates the merit of HR measures for determining if an individual is reactive to a sensory modality, although future investigations are needed to determine if various types and concentration of odors can elicit standard responses that affect HR. The changes in the water level by completely draining and adding back clean water resulted in too large of a disturbance to detect minor differences in HR. When the water was removed and the animals were on moist sand they immediately started to walk and wander. The walking movements caused large fluctuations in HR.

In reptiles, birds, and mammals the alterations in HR associated with the diving response can be offset by conditioning the animals as well as with other psychogenic influences (Butler and Jones, 1982; Gandevia et al., 1978). When some of these animals have been trained to immerse their heads into water, the level of bradycardia is often less marked than during forced submersion. This so called 'fear bradycardia' is one example of a psychogenic factor (Butler and Jones, 1982; Smith and Smeet, 1980). Likewise, in the crayfish possi- 
bly the expression of fear from the drastic changes in the water level resulted in the observed changes in HR.

The HR responsiveness in the blind cave crayfish to white light substantiates the observation that the animals are aware of the light, since behaviorally they will move and if the opportunity arises they prefer to remain in a shaded region of their environment. Previously it was demonstrated, in another blind cave adapted crayfish, Cambarus setosus that they had a caudal photoreceptor (Larimer, 1966). Work performed with the species used in this study demonstrated a behavioral response to white light, also suggesting a functional caudal photoreceptor ( $\mathrm{Li}$ and Cooper, 1999). Studies are under way to determine the minimum amount of light needed to alter HR and behavioral locomotive response, to determine how tightly coupled they are to each other.

In a recent study of using sighted crayfish, $P$. clarkii, it has been shown that HR measures were sensitive to visual signals, such as threatening posturing behaviors by the opponent. This study did not assess chemical or environmental disturbances effects on HR (Listerman et al., 2000). It is likely that the cave crayfish may have better chemosensory abilities as they can not make use of vision. Comparisons of olfactory responsiveness to HR changes between sighted and blind crayfish may be one way to determine sensitivity in eliciting a behavioral response. In addition, it was previously demonstrated that the magnitude and duration of an elevated HR was a result of exogenously administered serotonin in a dose-dependent manner. This study concluded that because HR could regain basal levels rapidly after an interaction for both winners and losers, systemic levels of serotonin were unlikely to be heightened as a result of winning, as was suggested by earlier studies (Livingston et al., 1980). The crustacean heart is very sensitive to serotonin as well as other peptides and neuromodulators (Cooke and Sullivan, 1982; Guirguis and Wilkens, 1995; Wilkens et al., 1985; Wilkens and McMahon, 1992; Wilkens and Walker, 1992; Yazawa and Kuwasawa, 1992; Wilkens and Mercier, 1993). In addition, receptor down regulation would tend to correct for the effects of chronically elevated serotonin levels (Fone et al., 1998). This should be manifested in command neurons as well because they regulate behaviors and reflexes which must be primed for additional modulation, which could either tune up or down the system. The significance of this work is that physiological measures of HR can be obtained in crayfish during different degrees of varying environmental disturbances as well as during social interactions. Previously, behavioral observations alone would have indicated that the animals were not responsive to stimuli that they were in fact aware of. The internal state of an individual's excitability appears not to be well measured by behavioral observations alone, but should be supplemented or replaced by physical measures. Possibly, by such measures of internal state and careful behavioral observations, predictive correlations will be possible.

\section{Acknowledgements}

Appreciation is given to Dr Hilary Lambert Hopper for editorial assistance. Funding was provided by a Howard Hughes Medical Institute undergraduate training fellowship (L.R.L.), NSFREU (L.R.L.), and NSF grants IBN-9808631 \& ILI DUE-9850907 (R.L.C.). This paper is dedicated to the late Cathy Crockett, who was a nationally recognized ecologically minded caver.

\section{References}

Atema, J., 1986. Review of sexual selection and chemical communication in the lobster, Homarus americanus. Can. J. Fish. Aquat. Sci. 43, 2283-2290.

Barr, T.C. Jr. 1985. Cave life of Kentucky. In: P.H. Dougherty (Eds.), Caves and Karsts of Kentucky. Kentucky Geological Survey, Special Publication 12, series XI. Univ. of Kentucky, Lexington.

Breithaupt, T., Atema, J., 1993. Evidence for the use of urine signals in agonistic interactions of the American lobster. Biol. Bull. 185, 318-323.

Bruski, C.A., Dunham, D.W., 1987. The importance of vision in agonistic communication of the crayfish Orconectes rusticus, 1. An analysis of bout dynamics. Behaviour 63, 83-107.

Burmistrov, Y.M., Shuranova, Z.P. 1996. Individual features in invertebrate behavior: Crustacea. In: Abramson C.I., Shuranova Z.P., Burmistrov Y.M., (Eds.), Russian Contributions to Invertebrate Behvavior. Praeger, Westport, Connecticut, pp. 111144.

Butler, P.J., Jones, D.R. 1982. The comparative physiology of diving in vertebrates. In: Lowenstein, O. (Eds.), Advances in Comparative Physiology and Biochemistry. Academic Press, New York, pp. 180326. 
Cheng, J.-H., Chang, E.S., 1991. Variations in urinary output of the lobster. J. Exp. Zool. 260, 288-294.

Cole, J.L., Li, H., Hopper, H.L., Cooper, R.L., 1998. The neuroecology of cave crayfish: The importance of tactile vs. visual cues in determining behavior as related to spatial learning \& social interaction. National Speleological Convention. Sewannee, TN. August 3-7, 1998.

Cooke, I.M., Sullivan, R.E., 1982. Hormones and neurosecretion. In: Bliss D.E. (Eds.), The biology of Crustacean Neurobiology: Structure and function. vol, 3. Academic Press, New York, pp. 206-290.

Cooper, R.L., Li, H., Cole, J.E., Hopper, H.L. 1998. The neuroecology of cave crayfish: Behavioral \& anatomical comparisons of vision in blind epigean species raised in a cave \& troglobitic species. Abst. Soc. Neurosci. 468. 10.

Cooper, R.L., Ruffner, M.E., 1998. Depression of synaptic efficacy at intermolt in crayfish neuromuscular junctions by 20 -hydroxyecdysone, a molting hormone. J. Neurophysiol. 79, 1931-1941.

Crider, M.E., Cooper, R.L., 1999. The importance of the stimulation paradigm'in determining facilitation and effects of neuromodulation. Brain Res. 842, 324-331.

Culver, D.C, Kane, T.C, and Fong, D.W. 1995. In: Culver, D.C, Kane, T.C, and Fong, D.W., (Eds.), Adaptation and Natural Selection in Caves. Harvard University Press, Cambridge, Mass.

Dudel, J., 1965. Facilitatory effects of 5-hydroxytryptamine on the crayfish neuromuscular junction. Naunyn-Schmiedebergs Arch. Exp. Path. Pharm. 249, 515-528.

Dunham, P.J., 1988. Pheromones and behavior in Crustacea. In: Laufer, H., Downer, R.G.H. (Eds.), Endocrinology of Selected Invertebrate Types. Alan R. Liss, New York, pp. 375-392.

Elwood, R.W., Wood, K.E., Gallagher, M.B., Dick, J.T.A., 1998. Probing motivational state during agonistic encounters in animals. Nature 393, 66-68.

Florey, E., Rathmayer, M., 1978. The effects of octoparnine and other amines on the heart and on the neuromuscular transmission in decapod crustaceans: further evidence for a role as a neurohormone. Comp. Biochem. Physiol. 61C, 229-237.

Fone, K.C., Austin, R.H., Topham, I.A., Kennett, G.A., Punhani, T., 1998. Effect of chronic m-CPP on locomotion, hypophagia, plasma corticosterone and 5-HT2C receptor levels in the rat. British $\mathrm{J}$. Pharm. 123, 1707-1715.

Gandevia, S.C., McCloskey, D.I., Patter, E.X., 1978. Reflex bradycardia, occurring in response to diving, nasopharyngeal stimulation and ocular pressure, and its modification by respiration and swallowing. J. Physiol. 276, 383-394.
Guirguis, M.S., Wilkens, J.L., 1995. The role of the cardioregulatory nerves in mediating heart rate responses to locomotion, reduced stroke volume and neurohormones in Homarus americanus. Biol. Bull. 188, 179-185.

Huber, R., Kravitz, E.A., 1995. A quantitative analysis of agonistic behavior in juvenile American lobsters (Homarus americanus L). Brain Behav. Evol. 46, $72-83$.

Hobbs, H.H. Jr, Barr, T.C., 1960. The origins and affinities of the troglobitic crayfishes of North American (Decapoda, Astacidae) 1. The genus Cambarus. Am. Midl. Nat. 64, 12-33.

Hobbs, H.H. Jr, Hobbs, H.H. III, Daniel, M.A., 1977. A review of the troglobitic decapod crustaceans of the Americas. Smithson. Contrib. Zoolog. 244, 1183.

Hofmann, H.A., Stevenson, P.A., 2000. Might restores fight in crickets. Nature 403, 613.

Karavanich, C., Atema, J., 1998. Olfactory recognition of urine signals in dominance fights between male lobster, Homarus americanus. Behaviour 135, 719730.

Larimer, J.L., 1966. A functional caudal photoreceptor in blind cavernicolous crayfish. Nature 21, 204-205.

Li, H., Huffman, P., Cole, J.L., Hopper H.L., Cooper, R.L. 1998. The neuroecology of cave crayfish: Spatial learning among the of blind cave crayfish. Abst. Soc. Neurosci. 468.8.

Li, H., Cooper, R.L. 1999. The neuroecology of the blind cave crayfish: social interactions. Am. Zoolog. 38: $201 \mathrm{~A}$.

Listerman, L., Doshi, D., Cooper, R.L., 1999. Measures of heart rate during social interactions and injections of serotonin in visual epigean and blind cave crayfish. East Coast Nerve Net, 25th Annual meeting. April 9-11 at MBL, Woods Hole, MA.

Listerman, L., Deskins, J., Bradacs, H., and Cooper, R.L., 2000. Measures of heart rate during social interactions in crayfish and effects of 5-HT. Comp. Biochem. Physiol. A. 125A, 251-263.

Livingston, M.S., Harris-Warrick, R.M., Kravitz, E.A., 1980. Serotonin and octoparnine produce opposite postures in lobsters. Science 208, 76-79.

McLeese, D.W., 1973. Orientation of lobsters (Homarus americanus) to odor. J. Fish Res. Board Canada 30, $838-840$.

McMahon, B.R., 1995. Integrated neural and neurohormonal control of respiratory and circulatory function in crustaceans: is there evidence for an 'autonomic' control system? Verh. Dtsch. Zool. Ges. 88.2, 87-101.

Pasztor, V.M., Bush, B.M.H., 1987. Peripheral modulation of mechanosensitivity in primary afferent neurons. Nature 326, 793-795. 
Pasztor, V.M., MacMillan, D.L., 1990. The actions of proctolin, octoparnine and serotonin on the crustacean proprioceptors show species and neurone specificity. J. Exp. Biol. 152, 485-504.

Rhoads, R., 1944. The crayfishes of Kentucky, with notes on variation, distribution and descriptions of species and subspecies. Am. Midl. Nat. 31, 111149.

Rhoads, R., 1962. The evolution of crayfishes of the genus Orconectes Section Limosus (Crustacea, Decapoda). Ohio J. Sci. 62, 65-96.

Smith, E.N., Smeet, D.J., 1980. Effect of atropine on the onset of fear bradycardia, in eastern cottontail rabbits. Comp. Biochem. Physiol. 66C, 239-241.

Sneddon, L.U., Taylor, A.C., Huntingford, F.A., Watson, D.G., 2000. Agonistic behavior and biogenic amines in shore crabs Carcinus maenas. J. exp. Biol. 203, 537-545.

Southard, R.C., Haggard, J., Crider, M.E., Whiteheart, S.W. and Cooper, R.L., 2000. Influence of serotonin on the kinetics of vesicular release. Brain Research 871, 16-28.

Strawn, J.R., Bonner, P.H., Cooper, R.L., 1999a. Motor command and synaptic transmission: Roles of
CNS, sensory systems, and neuromodulation. Abst. Soc. Neurosci. 25, 792.12.

Strawn, J.R., Neckameyer, W.S., Cooper, R.L., 1999b. The effects of 5-HT on sensory neurons, CNS command and neuromuscular junctions of the crayfish abdominal superficial flexor. Am. Zool. 39, 245A.

Wilkens, J.L., McMahon, B.R., 1992. Intrinsic properties and extrinsic neurohormonal control of the crab cardiac hemodynamics. Experientia 48, 827-834.

Wilkens, J.L., Mercier, A.J., 1993. Peptidergic modulation of cardiac performance in isolated hearts from the shore crab, Carcinus maenas. Physiol. Zool. 66, 237-256.

Wilkens, J.L., Mercier, A.J., Evans, J., 1985. Cardiac and ventilatory responses to stress and to neurohormonal modulators by the shore crab Carcinus maenas. Comp. Biochem. Physiol. 82C, 337-343.

Wilkens, J.L., Walker, R.L., 1992. Nervous control of the crayfish cardiac hemodynamics. Comp. Physiol. 11, 115-122.

Yazawa, T., Kuwasawa, K., 1992. Intrinsic and extrinsic neural and neuroliumoral control of the decapod heart. Experientia 48, 834-839. 